\title{
3D analysis of effects of primary surgeries in cleft lip/palate children during the first two years of life
}

\section{Karine Laskos SAKODA(a) Paula Karine JORGE(a) \\ Cleide Felício Carvalho CARRARA ${ }^{(b)}$ \\ Maria Aparecida de Andrade \\ Moreira MACHADO(a) \\ Fabrício Pinelli VALARELLI(c) \\ Arnaldo PINZAN(a) \\ Thais Marchini OLIVEIRA(a)}

(a) Universidade de São Paulo - USP, Bauru Dental School, Department of Pediatric Dentistry, Bauru, São Paulo, Brazil.

(b) Universidade de São Paulo - USP, Hospital for Rehabilitation of Craniofacial Anomalies, Department of Pediatric Dentistry, Bauru, São Paulo, Brazil.

(c) Universidade Ingá, Department of Orthodontics, Maringá, Paraná, Brazil.

Declaration of Interests: The authors certify that they have no commercial or associative interest that represents a conflict of interest in connection with the manuscript.

Corresponding Author:

Thais Marchini Oliveira

E-mail:marchini@usp.br

https://doi.org/10.1590/1807-3107BOR-2017.vol31.0046

Submitted: Mar 21, 2016

Accepted for publication: Mar 27, 2017

Last revision: Apr 25, 2017

\begin{abstract}
This study aimed at monitoring the maxillary growth of children with cleft lip/palate in the first two years of life, and to evaluate the effects of primary surgeries on dental arch dimensions. The sample consisted of the three-dimensional digital models of 25 subjects with unilateral complete cleft lip and palate (UCLP) and 29 subjects with isolated cleft palate (CP). Maxillary arch dimensions were measured at 3 months (before lip repair), 1 year (before palate repair), and at 2 years of age. Student's ttest was used for comparison between the groups. Repeated measures ANOVA followed by Tukey's test was used to compare different treatment phases in the UCLP group. Paired ttest was used to compare different treatment phases in the $C P$ group. $\mathrm{P}<0.05$ was considered statistically significant. Decreased intercanine distance and anterior arch length were observed after lip repair in UCLP. After palate repair, maxillary dimensions increased significantly, except for the intercanine distance in UCLP and the intertuberosity distance in both groups. At the time of palate repair and at two years of age, the maxillary dimensions were very similar in both groups. It can be concluded that the maxillary arches of children with UCLP and CP changed as a result of primary surgery.
\end{abstract}

Keywords: Cleft Lip; Cleft Palate; Growth and Development; Dental Models.

\section{Introduction}

Children with orofacial clefts undergo surgical and non-surgical multidisciplinary procedures that frequently cause adverse psychological consequences to the individuals and their families. ${ }^{1}$ The treatment of individuals with cleft lip/palate is complex, and its outcome is judged by obtaining a balance among factors of esthetics, speech, and facial growth. Problems of complex craniofacial growth are frequently observed in individuals with cleft lip and palate, and are generally reflected in transverse, anterior-posterior and vertical ${ }^{2}$ dental relationships.

Some studies suggest that repair surgeries play an important role in altering craniofacial growth and development. $t^{3,4,5}$ At the same time, other factors are also related to modifications in maxillo-mandibular growth: cleft width, amount of tissue present at birth, individual growth potential, ${ }^{6}$ surgical technique employed in the primary repair surgeries, ${ }^{7}$ surgical 
outcome $^{8}$ and the surgeon's ability. ${ }^{4,9}$ Some of the frequently reported adverse consequences of primary surgeries have been midface reduction, ${ }^{4,10}$ collapse of maxillary arches ${ }^{11}$ and presence of cross bite. ${ }^{12}$

Currently, the literature lacks information on the individual effects of lip and palate repair surgeries on maxillo-mandibular growth in the first years of life. A good understanding of the effects of primary surgeries is essential for the rehabilitation of the individuals with cleft lip/palate. The search for techniques to decrease the iatrogenic effects of the rehabilitative process may uncover more favorable outcomes that may consequently improve the quality of life of affected individuals. This study aimed at monitoring the maxillary growth of children with unilateral complete cleft lip and palate and isolated cleft palate in the first two years of life, and to evaluate the effects of primary surgeries on the dental arch dimensions.

\section{Methodology}

The Ethical Research Committee of the Hospital for the Rehabilitation of Craniofacial Anomalies of the University of São Paulo approved the protocol of this study (\#517.324). The inclusion criteria were children with cleft lip and palate and children with isolated cleft palate, born between 2010 and 2012, of both genders. Children presenting syndromes or associated malformations, and Simonart's band, and those having incomplete documentation were excluded from the study.

The sample size was calculated so that the number of selected children met the representative rating to conduct the study. Considering a prior study by Prahl et al., ${ }^{13}$ with a significance level of $5 \%$, test power of $80 \%$ and difference to be detected of 1.15 , the minimum sample size was calculated to be 24 individuals per group. Thus, the sample comprised 25 children with unilateral complete cleft lip and palate (group UCLP) and 29 children with isolated cleft palate (group CP).

Surgical procedures of lip repair followed Millard's technique. In regard to palate repair, von Langenbeck's technique was used for both groups. One surgeon performed all the surgical procedures on the same patient. Dental study casts of each patient were obtained at the following stages: T1 - Lip repair (UCLP), T2 - Palate repair (UCLP and CP) and T3 - 2 years of age (UCLP and CP). The impressions to obtain the casts of stages T1 and T2 were made before the surgeries.

The study casts were digitized (Scanner 3Shape R700 ${ }^{\mathrm{TM}}$ Scanner, Copenhagen, Denmark) and 3D OrthoAnalyzer ${ }^{\mathrm{TM}}$ software (Copenhagen, Denmark) was used to evaluate the measurements and to define the landmarks ${ }^{8}$ (Figure 1).
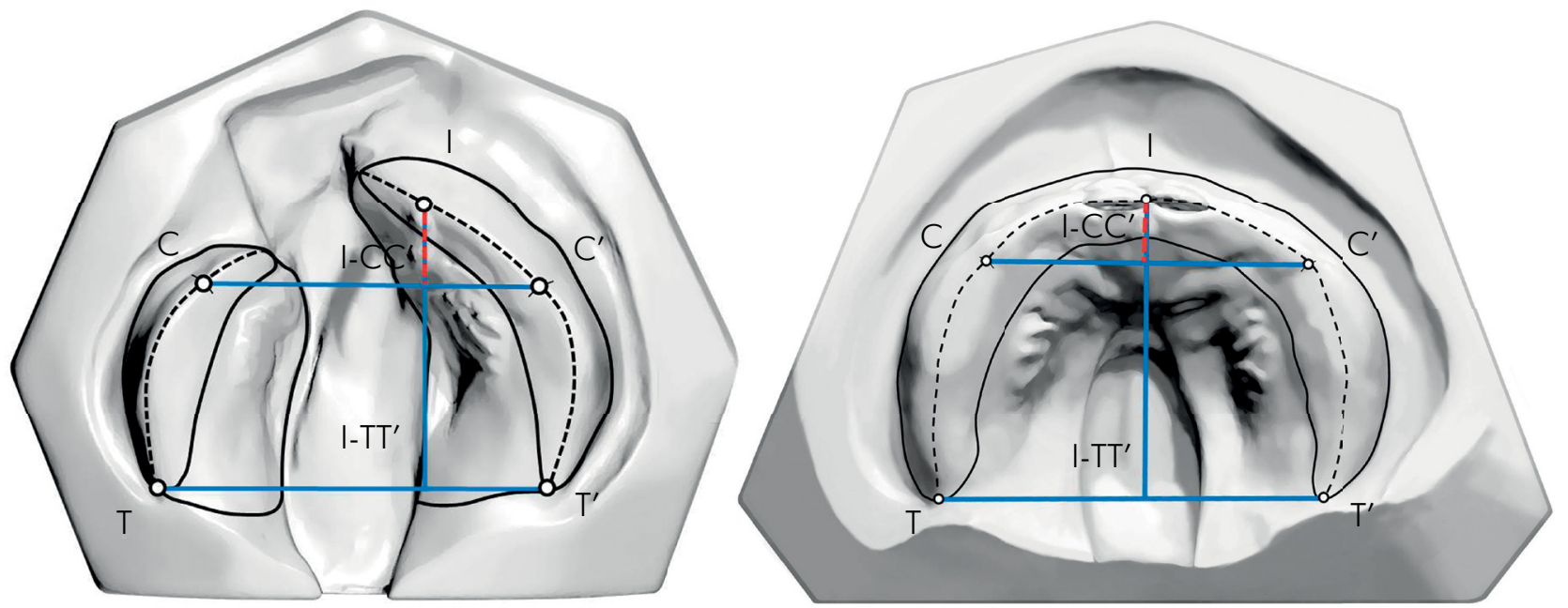

Figure 1. Landmarks and distances used for assessment: $C C^{\prime}$ (intercanine distance: where the lateral sulcus crosses the crest of the ridge); $\mathrm{TT}^{\prime}$ (intertuberosity distance: at the junction of the crest of the ridge with the outline of the tuberosity); I-CC' (anterior arch length. perpendicular from point I to line $\mathrm{CC}^{\prime}$ ); I-TT' (total arch length: perpendicular from point I to line $\mathrm{TT}^{\prime}$ ) 
Statistical analyses were performed with Statistica software (Statistica for Windows - Version 7.0 - StatSoft), by adopting a $5 \%$ level of significance. Intraexaminer error was analyzed by repeating the measurements 15 days after the first assessment, in 20 randomly selected study casts. Paired ttest was used to calculate the systematic error. The casual error was determined by Dahlberg's formula. The ttest was applied for intergroup comparisons. Repeated measures ANOVA was used for intragroup comparisons regarding different treatment stages in group UCLP, followed by Tukey's test. Paired ttest was applied to carry out the intragroup comparison for different treatment stages in group $\mathrm{CP}$.

\section{Results}

The intraexaminer test showed no statistically significant differences in the repeated measurements (Table 1). The mean ages of the children were compared at the different treatment stages, and are presented in Table 2. The lack of statistically significant differences among the evaluated mean ages enabled the comparison between the groups.

Maxillary dimensions of group UCLP at the different treatment stages are described in Table 3.

Table 1. Intraexaminer test - Paired Hest and Dahlberg's formula.

\begin{tabular}{|c|c|c|c|c|}
\hline \multirow{2}{*}{ Dimension } & $7^{\text {st }}$ measurement & $2^{\text {nd }}$ measurement & \multirow{2}{*}{ Dahlberg } & \multirow{2}{*}{$\mathrm{p}$} \\
\hline & Mean (SD) & Mean (SD) & & \\
\hline$C C^{\prime}$ & $29.78(2.85)$ & $29.66(2.84)$ & 0.432 & 0.410 \\
\hline $\mathrm{TT}^{\prime}$ & 34.80 (3.92) & 34.68 (3.78) & 0.475 & 0.434 \\
\hline I-CC' & $9.11(1.94)$ & $9.10(1.98)$ & 0.300 & 0.867 \\
\hline I-TT' & $27.75(2.90)$ & $27.81(2.72)$ & 0.367 & 0.639 \\
\hline
\end{tabular}

Table 2. Mean age (years) for UCLP and CP groups at different treatment stages.

\begin{tabular}{lccc}
\hline \multirow{2}{*}{ Stage } & UCLP & CP & \multirow{2}{*}{$P$} \\
\cline { 2 - 3 } & Mean (SD) & Mean (SD) & \\
\hline T1 & $0.39(0.12)$ & - & - \\
T2 & $1.13(0.10)$ & $1.16(0.17)$ & 0.339 \\
T3 & $2.21(0.19)$ & $2.18(0.36)$ & 0.697 \\
T3-T2 & $1.09(0.13)$ & $1.02(0.27)$ & 0.249 \\
\hline
\end{tabular}

$\mathrm{T} 1$ : lip repair; T2: palate repair; T3: 2 years of age
The intercanine distance $\left(\mathrm{CC}^{\prime}\right)$ decreased after lip repair, but remained stable from palate repair to 2 years of age. The intertuberosity distance (TT') showed a significant increase after lip repair. However, after palate repair, this distance did not exhibit significant changes. The anterior arch length (I-CC') decreased after lip repair and increased after palate repair. At 2 years of age, this variable showed smaller values than those obtained before the surgical procedures. The total arch length $\left(\mathrm{I}^{-T T} \mathrm{~T}^{\prime}\right)$ increased significantly in all periods evaluated.

The changes in the maxillary dimensions of group $\mathrm{CP}$ from palate repair to 2 years of age can be seen in Table 4. No significant changes were observed in TT' through the evaluated stages. The CC', I-CC', and I-TT' distances increased throughout the period studied.

The comparison of the maxillary dimensions between groups UCLP and CP at stages T2 and T3 is displayed in Table 5. None of the evaluated dimensions showed statistically significant differences between the groups.

Table 6 exhibits the changes in the maxillary dimensions occurring between stages $\mathrm{T} 2$ and $\mathrm{T} 3$. From palate repair to 2 years of age, only $\mathrm{CC}^{\prime}$ exhibited a significantly greater increase in group $\mathrm{CP}$.

Table 3. Maxillary dimensions ( $\mathrm{mm}$ ) of group UCLP - ANOVA, followed by Tukey's test.

\begin{tabular}{lcccc}
\hline \multirow{2}{*}{ Dimension } & T1 & T2 & T3 & \multirow{2}{*}{$P$} \\
\cline { 2 - 5 } & Mean (SD) & Mean (SD) & Mean (SD) & \\
\hline CC $^{\prime}$ & $31.24(2.83)^{a}$ & $29.60(3.01)^{b}$ & $30.20(2.80)^{b}$ & $<0.001^{*}$ \\
TT' $^{\prime}$ & $34.71(2.52)^{a}$ & $35.57(2.55)^{b}$ & $35.85(3.08)^{b}$ & $0.006^{*}$ \\
I-CC $^{\prime}$ & $9.29(1.26)^{a}$ & $7.55(1.27)^{b}$ & $8.14(1.56)^{c}$ & $<0.001^{*}$ \\
I-TT' $^{-T^{\prime}}$ & $26.96(2.08)^{a}$ & $28.78(2.69)^{b}$ & $30.46(2.34)^{c}$ & $<0.001^{*}$ \\
\hline
\end{tabular}

T1: lip repair; T2: palate repair; T3: 2 years of age. Groups with the same letter are not statistically different from each other (horizontal line); *Statistically significant difference.

Table 4. Maxillary dimensions (mm) of group CP - Paired ttest.

\begin{tabular}{lccc}
\hline \multirow{2}{*}{ Dimension } & T2 & T3 & P \\
\cline { 2 - 3 } & Mean (SD) & Mean (SD) & \\
\hline CC' $^{\prime}$ & $29.12(2.19)$ & $31.00(1.99)$ & $<0.001^{*}$ \\
TT' $^{\prime}$ & $34.67(2.48)$ & $34.84(2.75)$ & 0.671 \\
I-CC' & $7.15(1.50)$ & $8.19(1.47)$ & $<0.001^{*}$ \\
I-TT' & $28.11(1.92)$ & $30.80(2.08)$ & $<0.001^{*}$ \\
\hline T2: palate repair; T3 : 2 years of age; * statistically significant difference.
\end{tabular}


Table 5. Comparison of maxillary dimensions $(\mathrm{mm})$ between groups UCLP and CP at stages T2 (palate repair) and T3 (2 years of age) - Paired ttest.

\begin{tabular}{|c|c|c|c|c|c|c|}
\hline \multirow{3}{*}{ Dimension } & \multicolumn{3}{|c|}{ T2 } & \multicolumn{3}{|c|}{ T3 } \\
\hline & UCLP & $\mathrm{CP}$ & \multirow{2}{*}{$P$} & UCLP & $\mathrm{CP}$ & \multirow{2}{*}{$P$} \\
\hline & Mean (SD) & Mean (SD) & & Mean (SD) & Mean (SD) & \\
\hline $\mathrm{CC}^{\prime}$ & $29.60(3.01)$ & $29.12(2.19)$ & 0.505 & $30.20(2.80)$ & 31.00 (1.99) & 0.225 \\
\hline $\mathrm{TT}^{\prime}$ & $35.57(2.55)$ & $34.67(2.48)$ & 0.195 & 35.85 (3.08) & $34.84(2.75)$ & 0.205 \\
\hline I-CC' & 7.55 (1.27) & 7.15 (1.50) & 0.304 & $8.14(1.56)$ & $8.19(1.47)$ & 0.909 \\
\hline $\mathrm{I}-\mathrm{TT}^{\prime}$ & 28.78 (2.69) & $28.11(1.92)$ & 0.296 & $30.46(2.34)$ & 30.80 (2.08) & 0.583 \\
\hline
\end{tabular}

T2: palate repair; T3 : 2 years of age;

Table 6. Changes in maxillary dimensions $(\mathrm{mm})$ between stages T2 (palate repair) and T3 (2 years of age) - Paired ttest.

\begin{tabular}{lccc}
\hline \multirow{2}{*}{ Dimension } & UCLP & \multicolumn{1}{c}{$\mathrm{CP}$} & $\mathrm{P}$ \\
\cline { 2 - 3 } & Mean (SD) & Mean (SD) & \\
\hline $\mathrm{CC}^{\prime}$ & $0.60(1.06)$ & $1.88(1.53)$ & $<0.001^{*}$ \\
$\mathrm{TT}^{\prime}$ & $0.29(1.79)$ & $0.17(2.13)$ & 0.828 \\
$\mathrm{I}^{-} \mathrm{CC}^{\prime}$ & $0.59(1.09)$ & $1.04(1.40)$ & 0.205 \\
$\mathrm{I}^{-\mathrm{TT}^{\prime}}$ & $1.69(2.07)$ & $2.69(2.21)$ & 0.095 \\
\hline
\end{tabular}

*statistically significant difference.

\section{Discussion}

The present study results corroborate previous research on the analysis of dental arch dimensions before and after lip repair. ${ }^{13,14,15}$ In group UCLP, the maxillary dimensions for the anterior arch region (CC' and I-CC') diminished after lip repair, but I-TT' and TT' $^{\prime}$ showed a sizable increase. These results suggest that the modeling action and pressure exerted by the surgery after lip repair modified the maxillary segments in the anterior arch region ${ }^{4}$, rotating the segments towards the midline and decreasing the transverse diameter of the cleft. ${ }^{14}$ The reduced anterior maxillary dimensions indicated that the distorting effect of the surgery starts early ${ }^{16}$ and the immediate postoperative period is the most critical for maxillary retrusion. ${ }^{17,18}$ Growth restrictions caused by lip repair depend on cleft extension. Complete clefts impair maxillary growth to a greater extent, because they exhibit less resistance to the pressure exerted by the repaired lip, due to the lack of continuity of the alveolar ridge and palate. ${ }^{18}$

From when the palate was repaired up to two years of age, the anterior-posterior dimensions (I-CC' and I-TT') increased significantly in both groups. The $\mathrm{CC}^{\prime}$ remained stable in group UCLP, but increased significantly in group CP. The TT' did not undergo any change at this time (2 years), in the groups evaluated. This fact may indicate a greater interference of palate repair in group UCLP, by inhibiting transverse growth in the anterior and posterior regions. In group $\mathrm{CP}$, growth inhibition was more pronounced in the posterior region. This difference may be related to the presence of the alveolar cleft and the lack of arch continuity. Similar results for the findings of group $\mathrm{CP}$ were observed by Mazaheri et al. ${ }^{19}$ The authors related the similarity of the intertuberosity distance to the closure of the posterior palate. Honda et al. ${ }^{15}$ observed a decrease in $\mathrm{CC}^{\prime}$ and total arch length two years after palate closure in groups UCLP and CP.

When palate repair was performed, the maxillary dimensions in group UCLP were very similar to those of group CP. Other studies found similar results. ${ }^{15,19,20}$ The modeling action promoted by lip repair led to medial repositioning of the lateral-shifted maxillary segments in children with UCLP, resulting in good alignment of the dental arch and maxillary dimensions similar to those of children with $\mathrm{CP}$, without alveolar cleft.

At two years of age, the maxillary dimensions between the groups continued to be similar, as also observed by Mazaheri et al. ${ }^{19}$ Nevertheless, a greater increase in $\mathrm{CC}^{\prime}$ occurred in group CP. At 4 years of age, Honda et al. ${ }^{15}$ found no statistically significant differences in the intercanine and intertuberosity distances between children with UCLP and CP. However, the anterior and total arch length exhibited smaller values in children with UCLP in their study. Conflicting data were found by Mazaheri et al., ${ }^{19}$ 
who observed similar dimensions of the dental arches between the groups at four and five years of age. Generally, it is difficult to compare the results of different studies. The definition of the investigated parameters, therapeutic approaches and the observation period should be considered. ${ }^{21}$

No consensus has been reached as to which primary surgeries cause the greatest changes in maxillary growth. Additionally, few studies have evaluated isolated surgical effects. ${ }^{22,23}$ Studies comparing adults with UCLP, who had only their lip repaired, with those who had both their lip and palate repaired, reported the presence of maxillary retrusion in both groups, indicating that lip repair has an important restrictive effect on maxillary growth. ${ }^{22,23}$ On the other hand, many authors agree that palate repair causes adverse effects of variable severity on transverse and anterior-posterior maxillary growth. ${ }^{16,18,19,24}$ Kramer et al. ${ }^{25}$ verified that sagittal maxillary growth slows down immediately after hard palate closure. Kremenak et al. ${ }^{26}$ and Wijdeveld et al. ${ }^{27}$ confirmed this relationship with animal studies. Their studies showed that the healing tissue from palate repair led to the restriction of sagittal palatal growth. Thus, it can be assumed that both surgeries can influence maxillary growth, with greater interference of lip repair on the anterior arch region, and of palate repair on the transverse and sagittal direction of the maxilla.

The children in this study were treated at the same time periods, according to a uniform

\section{References}

1. World Health Organization. Global strategies to reduce the healthcare burden of craniofacial anomalies. Geneva: WHO; 2002.

2. Lilja J, Mars M, Elander A, Enocson L, Hagberg C, Worrell $E$ et al. Analysis of dental arch relationships in Swedish unilateral cleft lip and palate subjects: 20 -year longitudinal consecutive series treated with delayed hard palate closure. Cleft Palate Craniofac J. 2006;43(5):606-11. https://doi.org/10.1597/05-069

3. Athanasiou AE, Mazaheri M, Zarrinnia K. Longitudinal study of the dental arch dimensions in hard and soft palate clefts. J Pedod. 1987;12(1):35-47.

4. Ross RB. Treatment variables affecting facial growth in complete unilateral cleft lip and palate. Cleft Palate J. 1987;24(1):5-77. treatment protocol. Nevertheless, the study has some limitations. Although some studies indicate that sexual dimorphism may play a role in grow $\mathrm{th}^{6,28}$, the maxillary arch dimensions of boys and girls did not exhibit statistically significant differences among the observation periods. For this reason, the sample evaluated comprised both genders.

This study enabled the analysis of the early effects of primary surgeries on the dental arches of children with cleft lip/palate. Further studies following up both mixed and permanent dentition could provide better perspectives about the effect of primary surgeries on craniofacial growth and development.

\section{Conclusion}

From the results of the present study, it can be concluded that the maxillary arches of children with unilateral complete cleft lip and palate (UCLP) and isolated cleft palate $(\mathrm{CP})$ changed due to primary surgeries. Lip repair showed greater influence on the anterior arch region in group UCLP. Palate repair inhibited growth transversally in both groups, but this inhibition seemed to be greater in group UCLP.

\section{Acknowledgements}

The authors would like to acknowledge the financial support of the São Paulo Research Foundation (FAPESP grants \# 2010/13724-9 at TMO) and all the patients and families who helped us carry out this study.
5. Nakamura N, Suzuki A, Takahashi H, Honda Y, Sasaguri M, Ohishi M. A longitudinal study on influence of primary facial deformities on maxillofacial growth in patients with cleft lip and palate. Cleft Palate Craniofac J. 2005;42(6):633-40. https://doi.org/10.1597/03-151.1

6. Reiser E, Skoog V, Andlin-Sobocki A. Early dimensional changes in maxillary cleft size and arch dimensions of children with cleft lip and palate and cleft palate. Cleft Palate Craniofac J. 2013;50(4):481-90. https://doi.org/10.1597/11-003

7. Dahl E, Hanusardóttir $B$, Bergland $O$. A comparison of occlusions in two groups of children whose clefts were repaired by three different surgical procedures. Cleft Palate J. 1981;18(2):122-7. 
8. Witzel MA, Salyer KE, Ross RB. Delayed hard palate closure: the philosophy revisited. Cleft Palate J. 1984;21(4):263-9.

9. Andersson EM, Sandvik L, Semb G, Abyholm F. Palatal fistulas after primary repair of clefts of the secondary palate. Scand J Plast Reconstr Surg Hand Surg. 2008;42(6):296-9. https://doi.org/10.1080/02844310802299676

10. Doğan S, Onçağ G, Akin Y. Craniofacial development in children with unilateral cleft lip and palate.

Br J Oral Maxillofac Surg. 2006;44(1):28-33. https://doi.org/10.1016/i.bjoms.2005.07.023

11. Heidbuchel KL, Kuijpers-Jagtman AM, Kramer GJ, Prahl-Andersen B. Maxillary arch dimensions in bilateral cleft lip and palate from birth until four years of age in boys. Cleft Palate Craniofac J. 1998;35(3):233-9. https://doi.org/10.1597/1545-1569(1998)035<0233:MADIBC>2.3.CO;2

12. Reiser E, Skoog V, Gerdin B, Andlin-Sobocki A. Association between cleft size and crossbite in children with cleft palate and unilateral cleft lip and palate. Cleft Palate Craniofac J. 2010;47(2):175-81. https://doi.org/10.1597/08-219.1

13. Prahl C, Kuijpers-Jagtman AM, van't Hof MA, Prahl-Andersen B. A randomised prospective clinical trial into the effect of infant orthopaedics on maxillary arch dimensions in unilateral cleft lip and palate (Dutchcleft). Eur J Oral Sci. 2001;109(5):297-305. https://doi.org/10.1034/j.1600-0722.2001.00056.x

14. Wada T, Miyazaki T. Growth and changes in maxillary arch form in complete unilateral cleft lip and cleft palate children. Cleft Palate J. 1975;12(00):115-30.

15. Honda Y, Suzuki A, Ohishi M, Tashiro H. Longitudinal study on the changes of maxillary arch dimensions in Japanese children with cleft lip and/or palate: infancy to 4 years of age. Cleft Palate Craniofac J. 1995;32(2):149-55. https://doi.org/10.1597/1545-1569(1995)032<0149:LSOTCO>2.3.CO;2

16. Garrahy A, Millett DT, Ayoub AF. Early assessment of dental arch development in repaired unilateral cleft lip and unilateral cleft lip and palate versus controls. Cleft Palate Craniofac J. 2005;42(4):385-91. https://doi.org/10.1597/03-159.1

17. Bardach J, Bakowska J, McDermott-Murray J, Mooney MP, Dusdieker LB. Lip pressure changes following lip repair in infants with unilateral clefts of the lip and palate. Plast Reconstr Surg. 1984;74(4):476-81. https://doi.org/10.1097/00006534-198410000-00003

18. Kramer GJ, Hoeksma JB, Prahl-Andersen B. Palatal changes after lip surgery in different types of cleft lip and palate. Cleft Palate Craniofac J. 1994;31(5):376-84. https://doi.org/10.1597/1545-1569(1994)031<0376:PCALSI>2.3.CO;2

19. Mazaheri M, Harding RL, Cooper JA, Meier JA, Jones TS. Changes in arch form and dimensions of cleft patients. Am J Orthod. 1971;60(1):19-32. https://doi.org/10.1016/0002-9416(71)90179-5

20. Wada T, Mizokawa N, Miyazaki T, Ergen G. Maxillary dental arch growth in different types of cleft. Cleft Palate J. 1984;21(3):180-92.

21. Braumann B, Keilig L, Stellzig-Eisenhaver A, Bourauel C, Bergé $S$, Jäger $A$. Patterns of maxillary alveolar arch growth changes of infants with unilateral cleft lip and palate: preliminary findings. Cleft Palate Craniofac J. 2003;40(4):363-72. https://doi.org/10.1597/1545-1569(2003)040<0363:POMAAG >2.0.CO;2

22. Capelozza Filho L, Normando AD, da Silva Filho OG. Isolated influences of lip and palate surgery on facial growth: comparison of operated and unoperated male adults with UCLP. Cleft Palate Craniofac J. 1996;33(1):51-6. https://doi.org/10.1597/1545-1569(1996)033<0051:|IOLAP>2.3.CO;2

23. Li Y, Shi B, Song QG, Zuo H, Zheng Q. Effects of lip repair on maxillary growth and facial soft tissue development in patients with a complete unilateral cleft of lip, alveolus and palate. J Craniomaxillofac Surg. 2006;34(6):355-61 https://doi.org/10.1016/j.jcms.2006.03.005

24. Saperstein EL, Kennedy DL, Mulliken JB, Padwa BL. Facial growth in children with complete cleft of the primary palate and intact secondary palate. J Oral Maxillofac Surg. 2012;70(1):e66-71. https://doi.org/10.1016/i.joms.2011.08.022

25. Kramer GJ, Hoeksma JB, Prahl-Andersen B. Early palatal changes after initial palatal surgery in children with cleft lip and palate. Cleft Palate Craniofac J. 1996;33(2):104-11. https://doi.org/10.1597/1545-1569(1996)033<0104:EPCAIP>2.3.CO;2

26. Kremenak CR, Jr., Huffman WC, Olin WH. Maxillary growth inhibition by mucoperiosteal denudation of palatal shelf bone in non-cleft beagles. Cleft Palate J. 1970;7:817-25.

27. Wijdeveld MG, Maltha JC, Grupping EM, De Jonge J, Kuiipers-Jagtman AM. A histological study of tissue response to simulated cleft palate surgery at different ages in beagle dogs. Arch Oral Biol. 1991;36(11):837-43. https://doi.org/10.1016/0003-9969(91)90033-Q

28. Stellzig A, Basdra EK, Hauser C, Hassfeld S, Komposch G. Factors influencing changes in maxillary arch dimensions in unilateral cleft lip and palate patients until six months of age. Cleft Palate Craniofac J. 1999;36(4):304-9. https://doi.org/10.1597/1545-1569(1999)036<0304:FICIMA>2.3.CO;2 